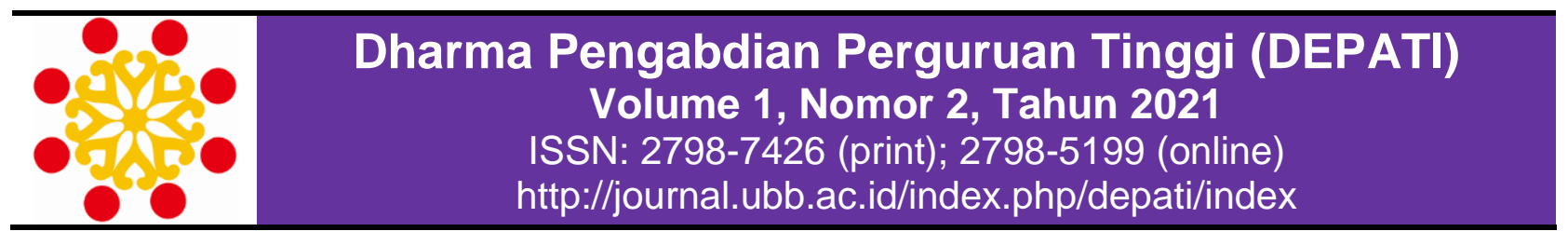

\title{
PELATIHAN KEMAMPUAN BERBICARA DALAM BAHASA INGGRIS MASYARAKAT PESISIR PANTAI WINI PERBATASAN NKRI-RDTL
}

\author{
Edmundus Bouk dan Desta Gloria Siahaan*) \\ Fakultas IImu Pendidikan, Universitas Timor \\ *E-mail korespondensi: destagloria9aan@unimor.ac.id
}

\begin{abstract}
Info Artikel: Abstract
Dikirim:

11 Oktober 2021

Revisi:

27 November

2021

Diterima:

29 November 2021

Kata Kunci:

The community service of the English Speaking Skills Training for the Wini Coastal Community at the NKRI-RDTL border was carried out by a service team, namely lecturers from the University of Timor. Wini Beach is located in North Insana District, North Central Timor Regency, East Nusa Tenggara. The training was held for 3 days at the Hamusu Wini Village Office and Wini Beach. The method used in this training is speaking test of role play between the seller/guide and foreign tourist. The number of community service participants is 30 , coming from various backgrounds, with range of 7 - 29 years old. After the training, it can be concluded that the trainees are able to speak in Engl ish. The service also suggested that similar training could be carried out to improve the knowledge and fluency of the Wini coastal community in speaking English.
\end{abstract}

Kemampuan,

berbicara,

bahasa inggris,

Wini, perbatasan

NKRI-RDTL

\begin{abstract}
Abstrak
Pengabdian Pelatihan Kemampuan Berbicara dalam Bahasa Inggris Masyarakat Pesisir Pantai Wini Perbatasan NKRI-RDTL dilakukan oleh tim pengabdi yaitu dosen dari Universitas Timor, kepada masyarakat pesisir Pantai Wini. Pantai Wini berlokasi di Kecamatan Insana Utara, Kabupaten Timor Tengah Utara, Nusa Tenggara Timur. Pelatihan dilaksanakan selama 3 hari di Kantor Desa Hamusu Wini dan Pantai Wini. Metode yang digunakan dalam pelatihan ini adalah bermain peran (Role Play) antara penjual atau guide dengan wisatawan asing. Adapun jumlah peserta pengabdian sebanyak 30 peserta, berasal dari latar belakang yang berbeda-beda, dengan rentang umur 7 - 29 tahun. Setelah melakukan pelatihan, dapat disimpulkan bahwa peserta pengabdian mampu berbicara dalam Bahasa Inggris. Pengabdi juga menyarankan agar pelatihan serupa bisa dilakukan untuk meningkatkan pengetahuan dan kelancaran masyarakat pesisir Pantai Wini dalam berbahasa Inggris.
\end{abstract}

\section{PENDAHULUAN}

Pantai Wini berlokasi di Kecamatan Insana Utara, Kabupaten Timor Tengah Utara, Nusa Tenggara Timur (Gambar 1). Tempat ini merupakan objek wisata pantai yang masih alami dengan hamparan pasir putih yang asri dan udara pantai yang begitu sejuk serta berbatasan dengan Republik Demokratik Timor Leste.

Pantai yang mumpuni sebagai tempat wisata, belum adanya pelatihan kemampuan berbicara dalam Bahasa Inggris masyarakat pesisir Pantai Wini di Desa Hamusu Wini dan Masyarakat yang bersedia belajar Bahasa Inggris menjadikan latar belakang dilakukannya pelatihan ini. Melalui pelatihan ini masyarakat diharapkan memiliki kemampuan berbahasa Inggris dalam berinteraksi dengan wisatawan asing yang datang melalui Indonesia maupun Timor Leste serta diharapkan dapat meningkatkan sektor Pariwisata di bidang pelayanan barang dan jasa dengan Bahasa Inggris sebagai media komunikasi di Nusa Tenggara Timur, khususnya di Kabupaten Belu, Kecamatan Kakuluk Mesak, Desa Hamusu Wini. 


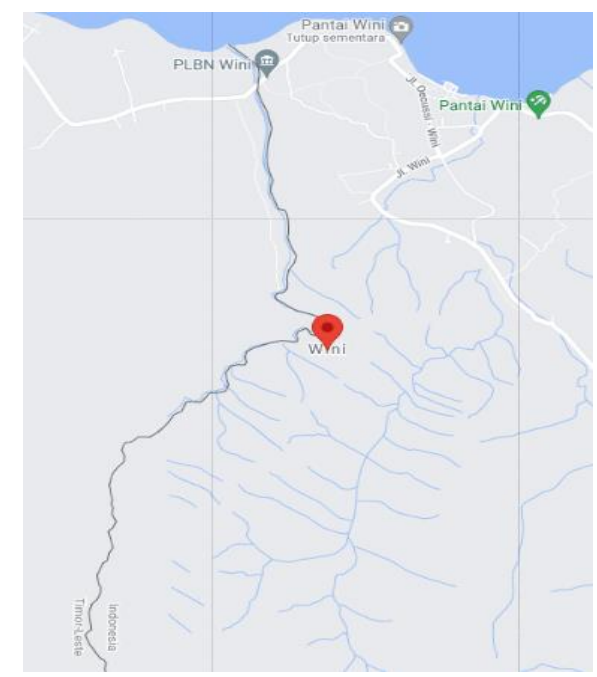

Gambar 1. Peta Pantai Wini

\section{TINJAUAN PUSTAKA}

\section{Kemampuan Berbicara}

Neno, Y. B., \& Siahaan, D. G. (2021) mengatakan berbicara adalah kegiatan yang melibatkan dua orang atau lebih di mana pesertanya adalah pendengar dan pembicara harus bertindak apa yang mereka dengar dan memberikan kontribusi mereka.Sebagai bahasa asing, bahasa Inggris memiliki empat keterampilan yang harus diajarkan dalam proses belajar mengajar. Keterampilan tersebut adalah mendengar, membaca, berbicara, dan menulis. Dari keempat keterampilan tersebut, keterampilan berbicara sangat penting untuk dipelajari karena ketika siswa belajar bahasa asing. Dianggap berhasil jika mereka dapat berkomunikasi secara efektif dalam bahasa kedua atau bahasa asing mereka.

Harmer (2001) menyatakan bahwa kemampuan berbicara lancar bukan hanya pengetahuan tentang ciri-ciri bahasa, tetapi juga kemampuan mengolah informasi dan bahasa 'on the spot'. Menurut Brown (2001), ada beberapa ciri yang menjadikan berbicara sebagai keterampilan berbahasa yang sulit. Mereka mencakup pengelompokan, redundansi, bentuk yang dikurangi, variabel kinerja, bahasa sehari-hari, pengiriman tingkat, stres, ritme, intonasi bahasa Inggris dan interaksi. Selain kurangnya kosa kata siswa, kurangnya kepercayaan diri mereka untuk berbicara dan menilai bahasa Inggris sebagai mata pelajaran yang sulit menjadikan berbicara sebagai keterampilan bahasa yang sulit.

\section{Tenses}

Tenses adalah bentuk-bentuk kata kerja yang digunakan pada sebuah klausa atau kalimat yang menjelaskan waktu suatu peristiwa terjadi. Adapun tenses yang diajarkan pada pelatihan ini adalah Simple Present Tense, Present Perfect Tense, Simple Past Tense dan Simple Future Tense dalam bentuk kalimat verbal dan kalimat nominal. Peserta juga dituntun mengubah bentuk kalimat positif menjadi negatif dan interogatif. Dengan pengajaran yang menyenangkan, peserta mampu membuat kalimat dalam berbagai tenses seperti; Simple Present Tense, Present Perfect Tense, Simple Past Tense dan Simple Future Tense dalam bentuk kalimat verbal dan kalimat nominal.

\section{Role playing atau bermain peran}

Role playing atau bermain peran merupakan permainan yang memerankan tokoh dalam suatu cerita, binatang, atau benda sekitar anak berdasarkan khayalan atau pengalaman seseorang yang melibatkan kemampuan berbicara [4]. Pendapat lain juga dikemukan oleh Nurul Ramadhani Makarao (2009) yang menyatakan bahwa Role Playing adalah suatu metode pelatihan yang memfasilitasi peserta untuk memainkan peran dalam skenario tertentu.

Secara teoritik metode bermain peran membutuhkan keterlibatan sebagian atau semua siswa dalam memerankan suatu tokoh atau benda, kondisi ini menuntut siawa untuk tidak diam, ia akan aktif, tidak statis, namun dinamis [6] 


\section{METODE PELAKSANAAN}

Metode yang digunakan dalam kegiatan pengabdian ini berupa pelatihan berbicara dalam bahasa inggris masyarakat pesisir Pantai Wini perbatasan NKRI-RDTL. Adapun metode pelatihan berbicara dalam Bahasa Inggris yang akan dilakukan sebagai berikut:

1. Survei Awal: survei dilakukan untuk meninjau lokasi pengabdian.

2. Identifikasi Masalah: minimnya pengetahuan berbahasa Inggris tentang interaksi dengan wisatawan asing dan kurangnya kemampuan berbicara dalam Bahasa Inggris.

3. Analisis Kebutuhan: pelatihan berbicara dalam Bahasa Inggris sangat dibutuhkan oleh masyarakat pesisir Pantai Wini untuk berinteraksi dengan wisatawan asing.

4. Sasaran: sasaran pelatihan berbicara dalam Bahasa Inggriss adalah masyarakat pesisir pantai yang ada di Desa Hamusu Wini.

5. Penyusunan Program: penetapan proposal, pelatihan berbicara dalam Bahasa Inggris, evaluasi kegiatan pelatihan dan penyusunan laporan akhir.

6. Pengukuran Indikator Keberhasilan: pengukuran Indikator Keberhasilan kegiatan ini ialah masyarakat pesisir Pantai Wini mampu berbicara dalam Bahasa Inggris, khususnya berbicara menggunakan kalimat tanya yang tepat, menjawab pertanyaan dengan pelafalan yang benar.

7. Pelaksanaan program: pelatihan berbicara dalam Bahasa Inggris dilaksanakan selama 3 hari dari 30 Juli 2021 sampai 1 Agustus 2021

\section{HASIL DAN PEMBAHASAN}

Adapun alur dari pelaksanaan pelatihan berbicara dalam Bahasa Inggris selama 3 hari ditunjukkan seperti pada Gambar 2.

Pengajaran jenis kata dalam Bahasa Inggris dan pembentukan kalimat verbal dan kalimat yang dilaksanakan pada hari pertama pelatihan.

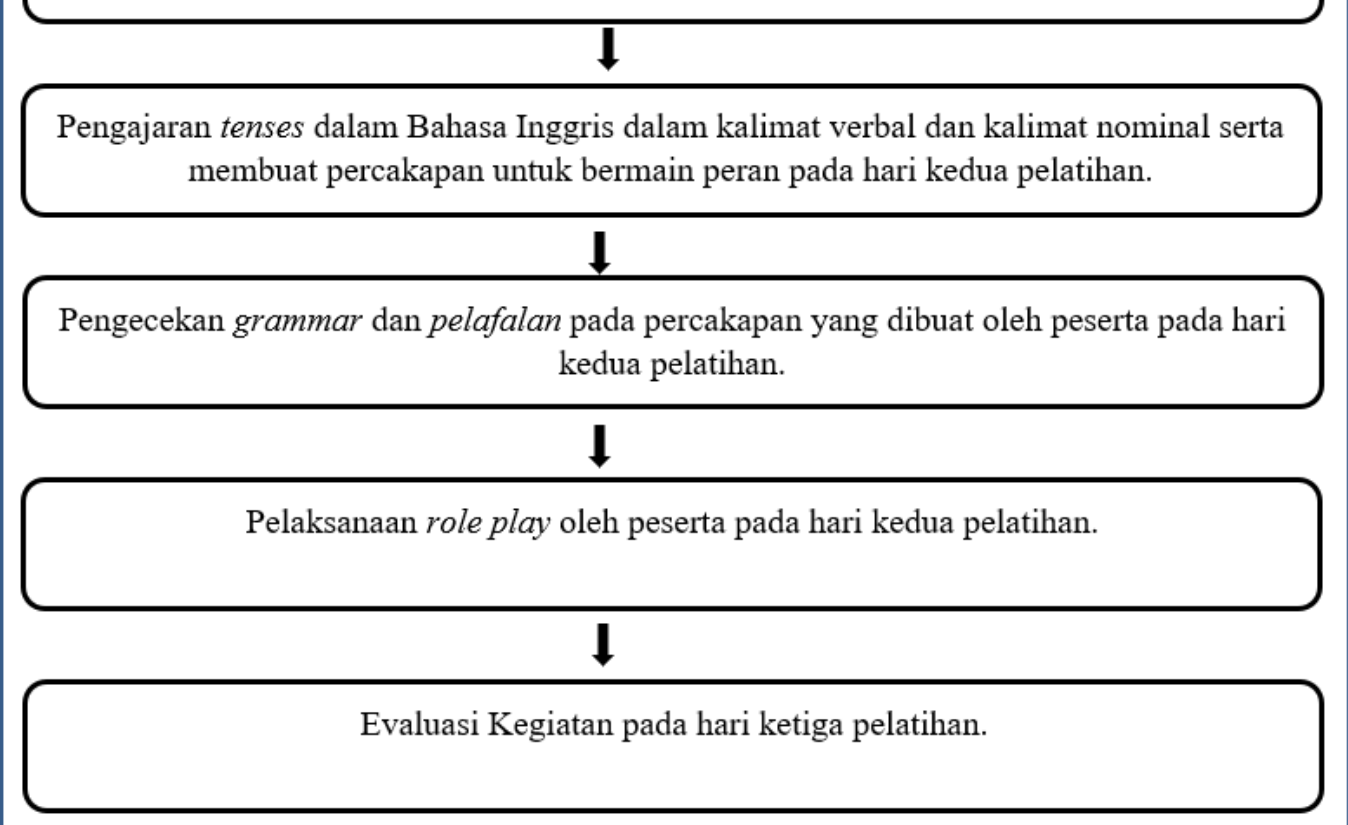

\section{Gambar 2. Alur pelaksanaa pelatihan berbicara dalam Bahasa Inggris}

Pengajaran jenis kata dalam Bahasa Inggris dan pembentukan kalimat verbal dan kalimat yang dilaksanakan pada hari pertama pelatihan (Gambar 3). Pengajaran jenis kata dalam bahasa Inggris sangat penting dilakukan agar peserta mampu merangkai kata-kata menjadi sebuah kalimat, baik kalimat verbal maupun kalimat nominal. Dengan pengajaran yang menyenangkan, peserta mampu membuat kalimat verbal dan nominal secara langsung. 


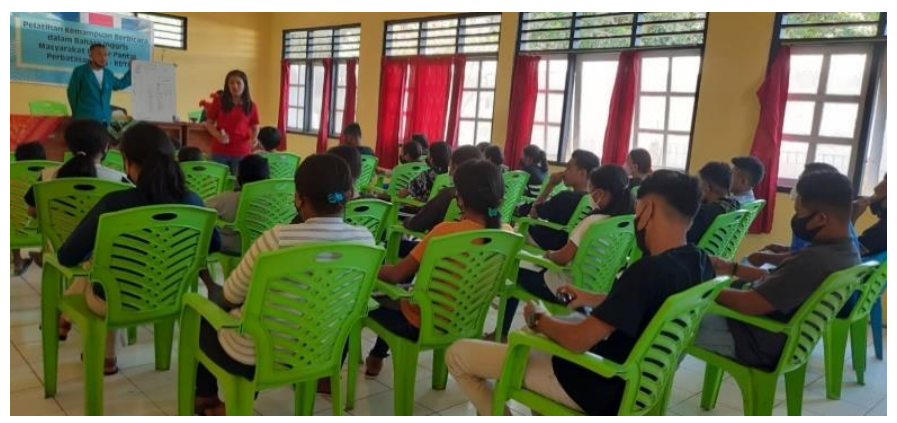

Gambar 3. Pengajaran jenis kata dalam bahasa Inggris dan pembentukan kalimat verbal dan kalimat yang dilaksanakan pada hari pertama pelatihan.

Pengajaran tenses dalam Bahasa Inggris dalam kalimat verbal dan kalimat nominal serta membuat percakapan untuk bermain peran pada hari kedua pelatihan (Gambar 4). Tenses yang diajarkan adalah Simple Present Tense, Present Perfect Tense, Simple Past Tense dan Simple Future Tense dalam bentuk kalimat verbal dan kalimat nominal. Peserta juga dituntun mengubah bentuk kalimat positif menjadi negatif dan interogatif. Dengan pengajaran yang menyenangkan, peserta mampu membuat kalimat dalam berbagai tenses seperti; Simple Present Tense, Present Perfect Tense, Simple Past Tense dan Simple Future Tense dalam bentuk kalimat verbal dan kalimat nominal.

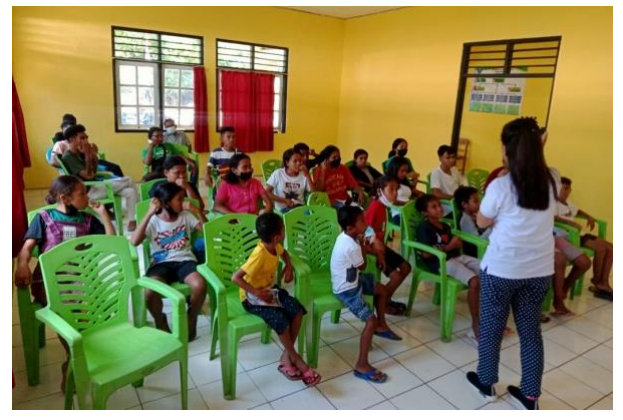

Gambar 4. Pengajaran tenses dalam Bahasa Inggris dalam kalimat verbal dan kalimat nominal serta membuat percakapan untuk bermain peran pada hari kedua pelatihan.

Pengecekan grammar dan pelafalan pada percakapan yang dibuat oleh peserta pada hari kedua pelatihan (Gambar 5). Setelah mengajarkan berbagai tenses, pengabdi meminta para peserta untuk membuat percakapan sendiri mengenai perkenalan, penawaran barang dan jasa, memberikan informasi antara wisatawan asing dan penjual atau pemandu/guide. Pengabdi juga melakukan pengecekan grammar dan pelafalan pada percakapan yang dibuat oleh peserta pada hari kedua pelatihan. Dalam proses pengecekan, masih terdapat kesalahan dalam grammar dan pelafalan yang dilakukan oleh para peserta. Dengan koreksi dan dukungan dari pengabdi, para peserta berlatih dengan sungguh-sungguh.

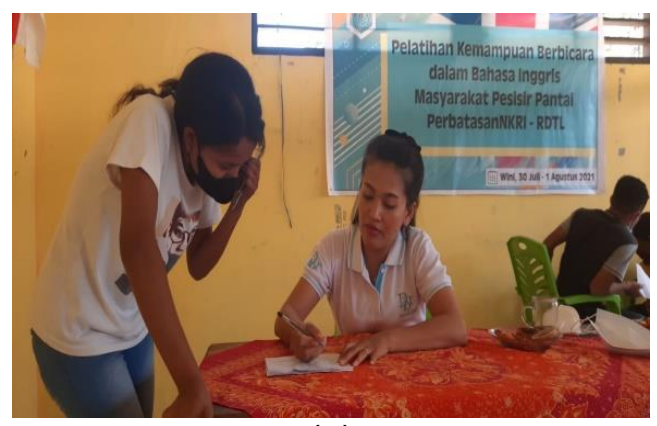

(a)

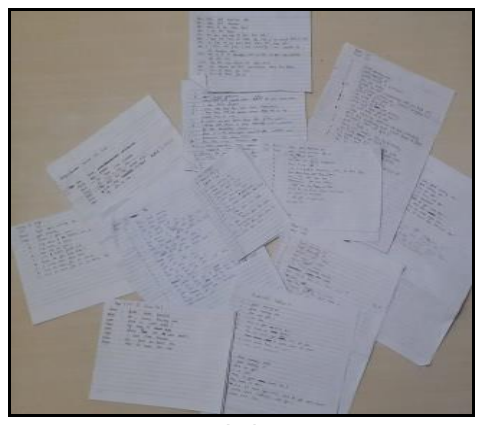

(b)

Gambar 5. (a) Pengecekan grammar dan pelafalan pada percakapan yang dibuat oleh peserta pada hari kedua pelatihan, (b) hasil percakapan yang sudah dikoreksi oleh pengabdi 
Pelaksanaan role play oleh peserta pada hari kedua pelatihan (Gambar 6). Peserta pelatihan dibebaskan untuk membuat topik sendiri dalam bermain peran/role play Adapun topik yang dipilih adalah perkenalan, penawaran barang dan jasa, memberikan informasi antara wisatawan asing dan penjual atau pemandu/guide dalam Bahasa Inggris. Adapun hasil dari Speaking Test dari peserta pengabdian dapat dilihat pada Tabel 1.

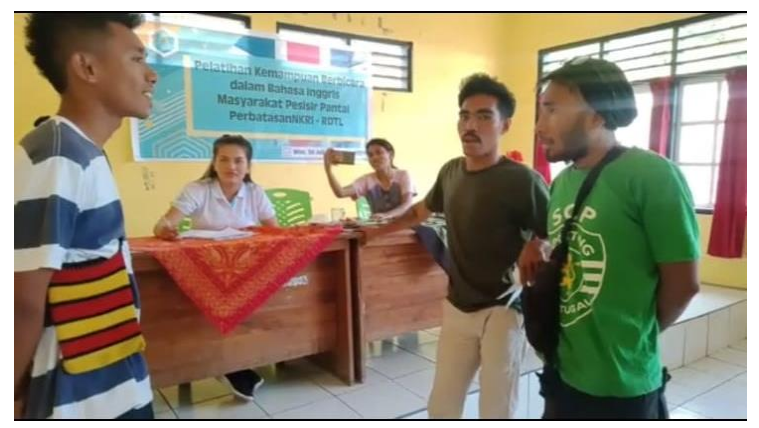

Gambar 6. Pelaksanaan role play oleh peserta antara dua wisatawan asing dengan pedagang di Pantai Wini pada hari kedua pelatihan.

Tabel 1. hasil dari Speaking Test dari peserta pengabdian

\begin{tabular}{cccccc}
\hline Grup & Grammar & Vocabulary & Fluency & Comprehension & Skor Akhir \\
\hline 1 & 85 & 90 & 80 & 85 & 85 \\
2 & 90 & 85 & 75 & 85 & 83.75 \\
3 & 75 & 75 & 75 & 75 & 75 \\
4 & 85 & 90 & 80 & 85 & 85 \\
5 & 85 & 70 & 80 & 85 & 80 \\
6 & 85 & 80 & 80 & 85 & 82.5 \\
7 & 85 & 90 & 80 & 85 & 85 \\
8 & 80 & 80 & 90 & 70 & 80 \\
9 & 75 & 90 & 75 & 80 & 80 \\
10 & 90 & 90 & 75 & 85 & 85 \\
11 & 80 & 90 & 75 & 75 & 80 \\
12 & 80 & 80 & 80 & 80 & 80 \\
\hline
\end{tabular}

Pelaksanaan role play berlanjut sampai hari ketiga pelatihan. Setelah mengevaluasi hasil kegiatan, pelatihan ini ditutup dengan foto bersama tim pengabdi dan para peserta pelatihan di Pantai Wini (Gambar 7).

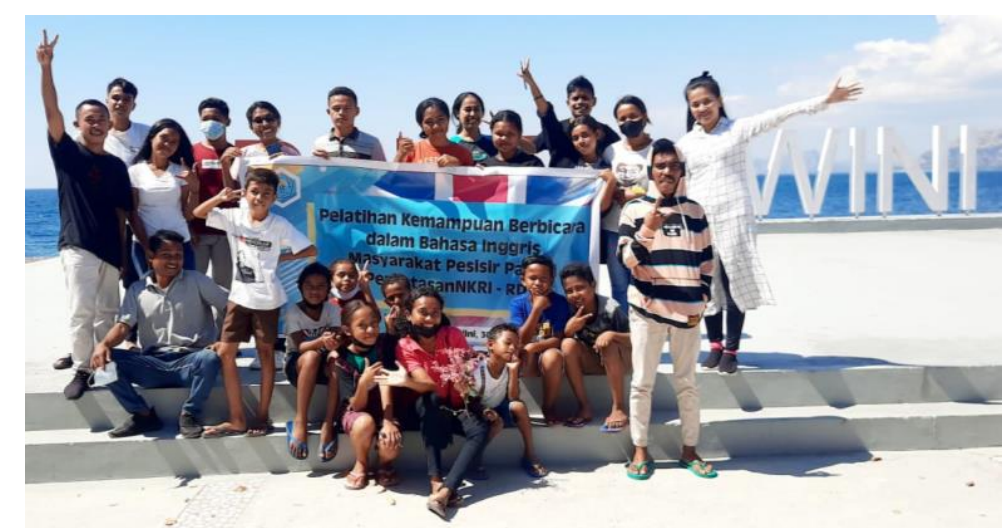

Gambar 7. Foto bersama tim pengabdi dan para peserta pelatihan di Pantai Wini

\section{KESIMPULAN}

Setelah melakukan kegiatan pengabdian kepada masyarakat adapun simpulan yang dapat dibuat adalah masyarakat pesisir Pantai Wini mampu berbicara dalam bahasa Inggris. 
Peserta mampu menguasai berbagai tenses seperti: Simple Present Tense, Present Perfect Tense, Simple Past Tense dan Simple Future Tense dalam bentuk kalimat verbal dan kalimat nominal. Peserta juga mampu mengubah bentuk kalimat positif menjadi negatif dan interogatif serta mampu melafakan kata dalam kalimat dengan baik. Nilai pada speaking test peserta dimulai dari 75 sampai dengan 90 .

\section{DAFTAR PUSTAKA}

[1] Neno, Y. B., \& Siahaan, D. G. (2021). Improving students' speaking ability through English club as an extracurricular at SMA Negeri 1 Kefamenanu. UNNES-TEFLIN National $\begin{array}{llll}\text { Seminar, 4(1), } & \text { 382-391. } & \text { Retrieved }\end{array}$ http://utns.proceedings.id/index.php/utns/article/view/131.

[2] Harmer, Jeremy. (2001). The Practice of English Language Teaching, 3rd Ed. New York: Longman, Inc.

[3] Brown, H.D. (2001). Teaching by Principles, an Interactive Approach to Langugae Pedagogy (2nd Ed.). New York: Pearson Education.

[4] Halida.(2011).Metode Bermain Peran dalam Mengoptimalkan Kemampuan Berbicara Anak Usia Dini (4-5 Tahun).Jurnal Cakrawala Kependidikan.Vol 9 (1):18.fileCUsersuserDownloads270-946-1-PB.pdf.

[5] Nurul Ramadhani Makarao. (2009). Metode Mengajar Dalam Bidang Kesehatan. Bandung: Alfabeta.

[6] Kartini, Tien. (2007). Penggunaan Metode Role Playing Untuk Meningkatkan Minat Siswa Dlam Pembelajaran Pengetahuan Sosial di Kelas V SDN Cileunyi I Kecamatan Cileunyi Kabupaten Bandung. Journal. (Online). www.today-pdf.net. 